\title{
Edoxaban in venous thromboembolism and stroke prevention: an appraisal
}

\author{
This article was published in the following Dove Press journal: \\ Vascular Health and Risk Management \\ 29 February 2016 \\ Number of times this article has been viewed
}

\author{
Marco Proietti ${ }^{1,2}$ \\ Gregory YH Lip ${ }^{1,3}$ \\ 'University of Birmingham Institute \\ of Cardiovascular Sciences, \\ City Hospital, Birmingham, UK; \\ ${ }^{2}$ Department of Internal Medicine \\ and Medical Specialties, Sapienza- \\ University of Rome, Rome, Italy; \\ ${ }^{3}$ Aalborg Thrombosis Research Unit, \\ Department of Clinical Medicine, \\ Aalborg University, Aalborg, Denmark
}

Correspondence: Gregory YH Lip University of Birmingham Institute of Cardiovascular Sciences, City Hospital, Dudley Road, Birmingham, West Midlands BI $87 \mathrm{QH}, \mathrm{UK}$

Tel +44 I2I 5075080

Fax +44 I2I 5544083

Email g.y.h.lip@bham.ac.uk
Abstract: Oral anticoagulation is the therapeutic cornerstone in preventing thromboembolic risk in both atrial fibrillation (AF) and venous thromboembolism (VTE). After decades of the sole therapeutic oral anticoagulation option being warfarin, the introduction of non-vitamin $\mathrm{K}$ antagonist oral anticoagulants has heralded a new era. Edoxaban is the latest addition to these available for clinical use. Edoxaban was as effective and safer than warfarin in preventing thromboembolic risk in AF patients. Similarly, edoxaban effectiveness and safety was evident when treating VTE patients to prevent recurrent VTE or VTE-related death. Therefore, edoxaban represents a valuable alternative in treating thromboembolic risk for AF and VTE patients.

Keywords: atrial fibrillation, venous thromboembolism, stroke, anticoagulation, edoxaban

\section{Introduction}

Oral anticoagulation is the therapeutic cornerstone in preventing thromboembolic risk in both atrial fibrillation (AF) ${ }^{1,2}$ and venous thromboembolism (VTE). ${ }^{3}$ AF is one of the most prevalent arrhythmias, ${ }^{4}$ and is associated with a fivefold increase in stroke risk. ${ }^{4}$ Stroke risk in AF increases with increasing age: for example, in AF patients aged 50-59 years, AF-related ischemic stroke incidence is approximately $4.6 \%$, and this progressively increases to approximately $20 \%$ in patients aged $80-89$ years. ${ }^{1}$ VTE, whether as deep venous thrombosis or pulmonary embolism, is common, with a global incidence of 108 events among whites and 78 events among blacks per 100,000 person-years in the USA. ${ }^{4,5}$ Moreover, VTE is associated with a high rate of mortality, and heavily affects health care-associated costs. ${ }^{5}$

Treatment with vitamin $\mathrm{K}$ antagonists (VKAs), such as warfarin or acenocoumarol, has traditionally been the therapeutic option in AF and VTE patients. ${ }^{3,6}$ While effective, VKAs require very close attention to the quality of international normalized ratio (INR) control, as reflected by the time in therapeutic range (TTR). ${ }^{6}$ Indeed, a TTR $>70 \%$ is recommended to achieve best efficacy and safety with VKAs. ${ }^{7,8}$ However, the TTR can be influenced by many common clinical factors, recently described by the SAMe-TT $\mathrm{R}_{2}$ score. $^{9-12}$

In the last decade, the development of non-VKA oral anticoagulants (NOACs; previously referred to as new or novel oral anticoagulants), ${ }^{13}$ have changed the pharmacological landscape and heralded a new era. In general, the NOACs have been proved to be as effective as VKAs, ${ }^{14}$ and sometimes also superior, ${ }^{15}$ in reducing thromboembolic stroke occurrence in nonvalvular AF (NVAF) $)^{16}$ and in treatment of acute and recurrent VTE. ${ }^{17}$ NOACs are also associated with a reduction in both major 
(especially intracranial) bleeding and any clinically relevant bleeding. ${ }^{17-19}$

The recent approval of edoxaban ${ }^{20}$ by the European Medicines Agency for the prevention of ischemic stroke and systemic thromboembolism in NVAF provides a range of therapeutic options with NOACs (apart from VKAs) for AF and VTE patients ${ }^{21}$ (Table 1). The aim of this review is to provide a comprehensive overview on the efficacy and safety of edoxaban in treating NVAF and VTE patients.

\section{Pharmacological profile of edoxaban}

Edoxaban is an oral direct factor-Xa inhibitor similar to the previously developed molecules rivaroxaban and apixaban. Previously known as DU-176b by International Union of Pure and Applied Chemistry name $N$-(5-chloropyridin-2-yl)- $N^{\prime}-[(1 S, 2 R, 4 S)-4-(N, N$-dimethylcarbamoyl)2 - (5-methyl-4,5,6,7-tetrahydrothiazolo [5,4-c] pyridine-2-carboxamido)-cyclohexyl]ethanediamide $p$-toluenesulfonate monohydrate, it was developed from the small anticoagulant molecule DX-9065a by Daiichi Pharmaceutical (Tokyo, Japan). ${ }^{22}$ DU-176b is a potent and highly selective factor-Xa inhibitor characterized by good oral bioavailability compared to its predecessor. ${ }^{22}$

Both animal and Phase I studies have demonstrated that DU-176b is highly effective in factor Xa-inhibition activity and reducing clot formation. In rat and monkey models, DU-176b showed almost complete inhibition of factor-Xa activity and (in particular in monkeys) a rapid onset of inhibitory effect. ${ }^{22}$

In 12 voluntary human subjects, oral administration of DU-176b provided significant clot-formation reduction up to 5 hours postdose, accompanied by parallel and

\section{Table I Edoxaban summary}

\begin{tabular}{ll}
\hline Route of administration & Oral \\
Onset of action & Rapid \\
Bioavailability & $62 \%$ \\
Development name & DU-I76b \\
IUPAC name & N-(5-chloropyridin-2-yl)- $N^{\prime}-[(I S, 2 R, 4 S)$ - \\
& $4-(N, N$-dimethylcarbamoyl)-2-(5-methyl- \\
& $4,5,6,7$-tetrahydrothiazolo[5,4-c]pyridine- \\
& 2-carboxamido)-cyclohexyl]ethanediamide \\
& p-toluenesulfonate monohydrate \\
& NVAF, VTE, major orthopedic surgery \\
Major indications & (only in Japan) \\
Pharmacology description & Factor Xa inhibitor \\
Approval route & Approved in the USA, Europe, and Japan \\
\hline
\end{tabular}

Abbreviations: IUPAC, International Union of Pure and Applied Chemistry; NVAF, nonvalvular atrial fibrillation; VTE, venous thromboembolism. consensual reduction in clotting parameters in both arterial and venous conditions. ${ }^{23}$ Moreover, changes in various routine and specific coagulation assays have also recently been described. ${ }^{24}$

Dose-finding research has shown that edoxaban yields a progressive, consistent, and predictable increase in plasma concentrations. ${ }^{25}$ Edoxaban quickly reaches peak plasma concentrations in 1.5 hours; its half-life is between 10 and 14 hours. Oral bioavailability is quite high (more than 62\%) and factor-Xa inhibition is highly selective, competitive, and concentration-dependent. ${ }^{25,26}$ Plasma concentrations of edoxaban are also closely correlated with the suppression of other coagulation indices and various platelet-activation parameters. $^{26}$

Given the renal route of elimination, pharmacokinetic changes in patients with renal impairment deserve attention. In patients with severe renal impairment (creatinine clearance $15-49 \mathrm{~mL} / \mathrm{min}$ ), a reduced edoxaban dose (15 mg once daily) resulted in similar plasma levels and adverse-event rates when compared with edoxaban 30 or $60 \mathrm{mg}$ once daily in patients with normal or mild renal (dys)function in short-term and medium-term follow-up (7 days of treatment). ${ }^{26}$ In patients with end-stage renal disease, hemodialysis treatment has only minimal effects on the clearance of edoxaban, so no further adjustment is needed. ${ }^{27}$

Few drug-drug interactions significantly affect edoxaban pharmacokinetics. No influence was found with the concomitant use of esomeprazole, atorvastatin, or naproxen. ${ }^{26}$ Neither atorvastatin, enoxaparin, nor low dose aspirin $(100 \mathrm{mg})$ influenced edoxaban exposure time. ${ }^{26}$ While digoxin did not influence edoxaban absorption, amiodarone and some agents, particularly dronedarone, quinidine, and verapamil (all of which are strong P-glycoprotein [P-gp] inhibitors), increased edoxaban exposure, requiring dose adjustment. ${ }^{26}$ No significant food interactions have been reported. ${ }^{26}$

\section{Edoxaban in nonvalvular atrial fibrillation}

Despite some drawbacks and limitations, particularly related to an excess of gastrointestinal bleeding (dabigatran $150 \mathrm{mg}$, rivaroxaban, edoxaban), gastrointestinal side effects (dyspepsia with dabigatran), and the need of ensuring adequate adherence to medication, ${ }^{28,29}$ NOACs have established themselves in current clinical practice for stroke prevention in NVAF patients.

Dabigatran, ${ }^{30}$ rivaroxaban, ${ }^{31}$ and apixaban ${ }^{15}$ are part of the current NOAC pharmacopoeias available for most of the European countries. In Europe, the approval of edoxaban 
adds another drug choice for patients with NVAF, helping physicians identify the best-choice treatment for any single patient.

Clinical trials performed thus far have clearly demonstrated both the efficacy and safety of edoxaban in preventing thromboembolism in AF. The pivotal trial for the approval in use for treating patients with NVAF was ENGAGE AF-TIMI 48 (Table 2). ${ }^{20,32}$ This was a three-arm, randomized, doubleblind, double-dummy trial comparing two dose regimens of edoxaban with warfarin. A total of 21,105 patients with documented AF within 12 months preceding randomization and with a $\mathrm{CHADS}_{2}$ score $\geq 2$ were randomized to receive edoxaban $30 \mathrm{mg}$, edoxaban $60 \mathrm{mg}$, or dose-adjusted warfarin to reach INR values between 2 and 3 .

During a median follow-up of 2.8 years, on-treatment analysis showed that the primary end point of stroke or systemic embolic event (SEE) in the warfarin group, despite good anticoagulation control with a median (interquartile range) TTR of $68.4 \%(56.5 \%-77.4 \%)$, was recorded in 232 patients at an overall rate of $1.50 \%$ per year, while patients in the high-dose edoxaban group reported 182 events $(1.18 \%$ per year) and patients in the low-dose edoxaban group reported 253 primary end-point events (1.61\% per year).

The hazard ratio (HR) for primary end point of high-dose edoxaban vs warfarin was 0.79 (97.5\% confidence interval [CI] $0.63-0.99, P<0.001$ for noninferiority), while lowdose edoxaban vs warfarin showed an HR of 1.07 (97.5\% CI $0.87-1.31, P=0.005$ for noninferiority). A superiority analysis failed to show a significant difference in the prespecified intention-to-treat analysis. Indeed, in this analysis the annualized rate of the primary end point was $1.80 \%$ in the warfarin group compared with $1.57 \%$ in the high-dose edoxaban group (HR vs warfarin 0.87, 97.5\% CI 0.73-1.04; $P=0.08$ ) and $2.04 \%$ in the low-dose edoxaban group (HR vs warfarin $1.13,97.5 \%$ CI $0.96-1.34, P=0.10)$.

For the secondary efficacy outcomes, treatment with highdose edoxaban was associated with lower annualized rates of death from cardiovascular causes than warfarin: $3.17 \%$ with warfarin compared with $2.74 \%$ with high-dose edoxaban (HR $0.86,95 \%$ CI $0.77-0.97 ; P=0.01)$ and $2.71 \%$ with low-dose edoxaban (HR 0.85, 95\% CI 0.76-0.96; $P=0.008$ ). Similar data were also reported for all-cause death.

The safety of edoxaban appears to be favorable. Phase II clinical trials showed that both low and high edoxaban doses had at the very least a similar safety profile to warfarin, with no significant increase in major or clinically relevant bleeding occurrence. ${ }^{33,34}$ These data were then reinforced with the Phase III ENGAGE AF-TIMI 48 study, where major bleeding events were significantly higher in patients treated with warfarin $(3.43 \%$ /year) compared to those on high-dose edoxaban (2.75\%/year, HR vs warfarin $0.80,95 \%$ CI $0.71-0.91 ; P<0.001)$ or low-dose edoxaban (1.61\%/year, HR vs warfarin $0.47,95 \% \mathrm{CI} 0.41-0.55 ; P<0.001)$. Also, the rates of life-threatening bleeding, intracranial bleeding, and major bleeding plus clinically relevant nonmajor bleeding were consistently higher in warfarin-treated patients than in either edoxaban dose. ${ }^{20}$

When the net clinical benefit (NCB) of edoxaban was assessed, the rates for the composite net clinical primary outcome of death from any cause/stroke/SEE/major bleeding were significantly lower with both edoxaban regimens compared to warfarin: $8.11 \%$ with warfarin compared with $7.26 \%$ with high-dose edoxaban (HR 0.89, 95\% CI 0.83-0.96; $P=0.003$ ) and $6.79 \%$ with low-dose edoxaban (HR 0.83, 95\% CI $0.77-0.90 ; P<0.001$ ). With regard to secondary (death from any cause/disabling stroke/life-threatening bleeding) and tertiary (stroke/SEE/life-threatening bleeding/death from any cause) net clinical outcomes, significantly lower rates were found with both edoxaban doses. ${ }^{20}$

Recently, a large comprehensive meta-analysis, combining all the edoxaban studies performed in NVAF patients, confirmed that edoxaban had the same efficacy and a better safety profile than warfarin in treating thromboembolic risk. ${ }^{35}$ In particular, this meta-analysis confirmed that the better safety profile was consistent independently of the type of bleeding event (major/minor/clinically relevant nonmajor bleeding). In the same paper, a direct comparison between the two edoxaban regimens showed that both low- and high-dose edoxaban were effective in reducing both thromboembolic events and all-cause mortality. ${ }^{35}$ Last,

Table 2 Phase III randomized clinical trials evaluating edoxaban efficacy and safety

\begin{tabular}{llllll}
\hline Study & Year & Study groups & Patients & Mean FU & Primary outcome \\
\hline ENGAGE AF-TIMI 4820 & 2009 & Edoxaban 60 mg OD & 7,035 & 2.8 years & Stroke/SEE \\
& & Edoxaban 30 mg OD & 7,034 & & \\
& & Dose-adjusted warfarin (INR 2-3) & 7,036 & \multirow{2}{*}{ Recurrent } \\
Hokusai-VTE & & Edoxaban 60 mg OD & 4,118 & 8.2 months & symptomatic VTE \\
\hline
\end{tabular}

Abbreviations: FU, follow-up; INR, international normalized ratio; OD, once daily; SEE, systemic embolic event; VTE, venous thromboembolism. 
edoxaban $30 \mathrm{mg}$ was associated with a lower incidence of all bleeding events. ${ }^{35}$

A subanalysis of the dose-reduction strategy of ENGAGE AF-TIMI 48 was recently published. ${ }^{36}$ This study showed that edoxaban dose adjustment according to concomitant clinical factors did not affect efficacy and conferred a better safety profile. Indeed, when high-dose edoxaban was considered, no difference was found in efficacy for the primary outcome independently of dose reduction (HR for no dose reduction vs warfarin in preventing stroke/SEE $0.78,95 \% \mathrm{CI}$ 0.61-0.99; HR for dose reduction vs warfarin in preventing stroke/SEE $0.81,95 \%$ CI $\left.0.58-1.13 ; P_{\text {interaction }}=0.85\right)$, giving even greater safety (HR for no dose reduction vs warfarin for major bleeding 0.88 , 95\% CI 0.76-1.03; HR for dose reduction vs warfarin in preventing stroke/SEE $0.63,95 \% \mathrm{CI}$ $\left.0.50-0.81 ; P_{\text {interaction }}=0.023\right)$. Similar data were found for lowdose edoxaban. These results were consistent independently of the factors used to establish the need for a dose-reduction strategy. ${ }^{36}$

One recent paper investigating the NCB of edoxaban through a modeling strategy applied to a large population of NVAF patients, according to standard rates of stroke/ SEE and major bleeding, showed that edoxaban had a better NCB than warfarin, preventing 0.71 strokes/SEE events per 100 patient-years for both low-dose and high-dose edoxaban compared to 0.26 events per 100 patient-years prevented with warfarin. ${ }^{37}$ Compared to no treatment, both edoxaban regimens were found to have a better NCB than warfarin at all $\mathrm{CHA}_{2} \mathrm{DS}_{2}$-VASc scores, particularly so in high-risk patients $\left(\mathrm{CHA}_{2} \mathrm{DS}_{2}\right.$-VASc score $\left.\geq 2\right){ }^{37}$

A recent analysis based on indirect comparisons between the four NOACs reported that edoxaban $60 \mathrm{mg}$ once daily would be as effective as rivaroxaban, apixaban, and dabigatran $110 \mathrm{mg}$ twice daily, while dabigatran $150 \mathrm{mg}$ twice daily was more effective than edoxaban $60 \mathrm{mg}$ once daily. ${ }^{38,39}$ Indirect comparisons on the efficacy and safety of edoxaban vs aspirin and no therapy have also been reported. ${ }^{40}$ However, indirect comparisons have many limitations, and given that we have four NOACs as well as warfarin, it would be prudent to fit the particular NOAC drug to the particular patient profile (and vice versa). ${ }^{41}$ In patients more likely taking once-daily drugs, edoxaban could be preferable to rivaroxaban in relation to the associated lower bleeding risk with edoxaban. ${ }^{39}$ Furthermore, in patients needing a reduced-dose regime, edoxaban $30 \mathrm{mg}$ could be preferred to dabigatran $110 \mathrm{mg}$ twice daily or apixaban, given the lowest risk of major bleeding.

One other randomized clinical trial is also ongoing with edoxaban in NVAF. The ENSURE-AF (NCT02072434) trial aims to evaluate the efficacy and safety of edoxaban in the treatment of subjects undergoing elective electric cardioversion. ${ }^{42}$ The study is a prospective, randomized, open-label, blinded, end-point evaluation, parallel-group, Phase IIIB study comparing edoxaban with an enoxaparin/warfarin regimen in the prophylactic anticoagulant treatment related to the cardioversion procedure. The primary end point is a composite outcome of stroke, SEE, myocardial infarction, and cardiovascular mortality from randomization up to 56 days after the procedure. The safety end point is the composite of major and clinically relevant nonmajor bleeding up to the end of anticoagulant treatment after 28 days postprocedure. ${ }^{42}$ Results from this trial could be very valuable in targeting the clinical role of edoxaban in treating AF patients for this specific indication.

In summary, the role of edoxaban in ensuring adequate protection for stroke/SEE events and adequate safety in NVAF seems to be consistent across various clinical conditions, though real-life data about efficacy and safety are still needed, in particular to clarify efficacy and safety in various clinical subgroups. Specific safety and efficacy data on elderly patients or patients with higher frailties are currently still lacking for edoxaban. Until now, virtually all data related to edoxaban safety and efficacy have come from industry-sponsored trials, and thus independent observational data are needed to further confirm the NCB for edoxaban in real-world AF populations. Despite being the most recent NOAC approved for use in Europe, its properties, such as the once-daily regimen, along with the lower bleeding risk and consistency of effect in patients with renal impairment when a reduced dose is prescribed, could help the decision-making process to assign the proper NOAC drug for treatment of the right patient. ${ }^{41}$

\section{Use of edoxaban in symptomatic venous thromboembolism treatment}

Effective treatment for VTE is clearly needed to reduce the risk of recurrent VTE and its associated complications. ${ }^{43}$ Similarly to AF, treatment of patients with VTE requires adequate strategies to balance the risks of VTE recurrence and bleeding. ${ }^{3}$ These new drugs have clearly been demonstrated to be as effective as warfarin in reducing the risk of recurrent VTE. ${ }^{44}$ Furthermore, NOACs show a better safety profile, with the consistently lowest risk of major bleeding across all studies. ${ }^{44}$

The efficacy and safety of edoxaban in the treatment of symptomatic VTE were tested in the Hokusai-VTE study ${ }^{45,46}$ 
(Table 2). Hokusai-VTE was a randomized double-blind, double-dummy, parallel-group, noninferiority trial comparing edoxaban $60 \mathrm{mg}$ and warfarin after enoxaparin/unfractionated heparin lead-in treating patients admitted with symptomatic VTE. ${ }^{45}$ Hokusai-VTE has been the largest study ever conducted in this clinical setting, enrolling 8,292 patients from January 2001 to October 2012 across 439 centers in 37 countries. $^{47}$

Among the total study cohort, 4,921 patients were diagnosed with deep venous thrombosis, while 3,319 were found to have a pulmonary embolism. The primary efficacy outcome was occurrence of the composite outcome of first recurrent VTE/VTE-related death. Treatment with edoxaban or warfarin was continued for at least 3 months and no more than 12 months, with $40 \%$ of the total cohort treated up to 12 months. Edoxaban was as effective as warfarin in preventing primary outcome occurrence when compared with warfarin (HR for edoxaban vs warfarin 0.89 , 95\% CI $0.70-1.13 ; P<0.001$ for noninferiority). Moreover, edoxaban was safer than warfarin in preventing the occurrence of the primary safety outcome of first major or clinically relevant nonmajor bleeding (HR for edoxaban vs warfarin $0.81,95 \%$ CI $0.71-0.94 ; P=0.004$ for superiority). Similar data were found for the safety outcome of clinically relevant nonmajor bleeding $(P=0.004)$ and the occurrence of any bleeding $(P<0.001)$. Conversely, no significant difference was found for the occurrence of major bleeding (HR for edoxaban vs warfarin $0.84,95 \% \mathrm{CI}$ $0.59-1.21 ; P=0.35)$. No significant difference was found in NCB between edoxaban and warfarin (HR 0.83, 95\% CI $0.65-1.06 ; P=0.14)$.

Subgroup analysis showed no profound difference for most subgroup analyses. In the occurrence of the primary outcome, only fragile patients were more successfully treated than patients with no fragilities $(P=0.0408)$. Safety outcomes were significantly reduced in male-subgroup patients $(P=0.0041)$ and in Asian patients $(P=0.0266)$. Interestingly, center-level INR TTR for warfarin subjects $<60 \%$ discriminated the occurrence of primary safety outcome $(P=0.0175)$, but not the occurrence of primary efficacy outcome $(P=0.9136)$.

A prespecified post hoc analysis of patients with active/history of cancer also reported that in this large subgroup, edoxaban was both effective and safe in preventing recurrent VTE. ${ }^{47}$ Since the number of patients in this specific subgroup was small $(n=771)$, the Hokusai VTE-cancer study, a randomized, open-label, clinical trial, is ongoing to evaluate whether edoxaban is noninferior to low-molecular-weight heparin for treatment of VTE in patients with cancer. ${ }^{48}$

The effect of edoxaban in East Asian patients was confirmed by a subgroup analysis, showing lower primary outcome occurrence rates in edoxaban than in warfarin $(2.8 \%$ vs $4.5 \%) .{ }^{49}$ Edoxaban was also noninferior to warfarin in this specific population (HR for primary outcome vs warfarin $0.64,95 \%$ CI $0.34-1.19 ; P=0.1601) .{ }^{49}$ The safer profile compared to warfarin was confirmed in East Asian patients, with a primary safety outcome that occurred significantly less often in the edoxaban group than in warfarin-treated patients $(9.9 \%$ vs $17.3 \%$, respectively, HR 0.56 , 95\% CI $0.40-0.78 ; P<0.001) .{ }^{49}$

More recently, an indirect comparison between the four NOACs on efficacy and safety in preventing recurrent VTE was published. No significant differences were found between NOACs for the occurrence of the primary outcome of recurrent VTE/VTE-related death. ${ }^{44}$ For the safety outcome of major and clinically relevant nonmajor bleeding, apixaban was the safest NOAC. ${ }^{44}$ Despite that, edoxaban was found to be the only NOAC to be significantly safer than warfarin for the occurrence of fatal bleeding episodes. ${ }^{44}$ Therefore, edoxaban appears to be a valuable alternative in treating VTE patients, especially those of East Asian ethnicity and those with active cancer.

\section{Reversal strategies and management of bleeding complications}

Since NOACs' introduction to clinical practice, the most relevant concern with them has been the lack of any specific direct reversal strategy. ${ }^{50}$ Even if all NOACs have been reported as safer than warfarin, given their short half-life, the anticoagulant effect is expected to wear off much earlier after any bleeding episode compared to warfarin-treated patients. Therefore, several attempts have been made to identify better strategies to manage bleeding complications, ${ }^{50}$ which have recently been summarized in an European Society of Cardiology position paper. ${ }^{51}$

Of note, specific antidotes have recently been made available for dabigatran, ${ }^{52-54}$ as well as for apixaban and rivaroxaban..$^{55}$ In a recent study among healthy subjects, andexanet alpha was able to reverse the anticoagulant effect of both apixaban and rivaroxaban in $94 \%$ and $96 \%$ of subjects, respectively. ${ }^{55}$ Though no specific data have been formally published, the use of andexanet alpha in edoxaban-treated patients also would seem a promising strategy to reverse the latter's anticoagulant effects. 


\section{Conclusion}

NOACs have changed the landscape for thromboprophylaxis in $\mathrm{AF}_{,}^{13,28,29}$ and the challenge now is to translate the clinical trials to everyday practice. Gaps in translation remain, ${ }^{28}$ as do unanswered questions. ${ }^{56}$ Particular benefits of NOACs are especially evident in Asian patients, who tend to do less well on warfarin compared to non-Asians ${ }^{57}$ The availability of different NOACs enables us to fit the NOAC agent to the patient profile, and vice versa. ${ }^{41}$

On a more specific note, edoxaban represents a valuable alternative to warfarin in treating thromboembolic risk for $\mathrm{AF}$ and VTE patients. Clinical trial data with edoxaban are compelling for efficacy and safety. The absence of real-world observational data on the efficacy and safety of edoxaban in everyday clinical practice is evident, and such data are clearly needed.

\section{Disclosure}

GYHL has participated in steering committees and trials, including steering committees for various Phase II and III studies and health economics and outcomes research, and been cochair of the ENSURE-AF trial with edoxaban, an investigator in various clinical trials in cardiovascular disease, including those on antithrombotic therapies in $\mathrm{AF}$ acute coronary syndrome, and lipids, a consultant for Bayer/ Janssen, Astellas, Merck, Sanofi, BMS/Pfizer, Biotronik, Medtronic, Portola, Boehringer Ingelheim, Microlife, and Daiichi-Sankyo, a speaker for Bayer, BMS/Pfizer, Medtronic, Boehringer Ingelheim, Microlife, Roche, and Daiichi Sankyo, and has received a nonpromotional departmental educational research grant for a postdoctoral research fellow from DaiichiSankyo. MP reports no conflicts of interest in this work.

\section{References}

1. Lip GY, Lane DA. Stroke prevention in atrial fibrillation: a systematic review. JAMA. 2015;313(19):1950-1962.

2. Camm AJ, Lip GY, De Caterina R, et al. 2012 Focused update of the ESC guidelines for the management of atrial fibrillation: an update of the 2010 ESC guidelines for the management of atrial fibrillation. Developed with the special contribution of the European Heart Rhythm Association. Eur Heart J. 2012;33(21):2719-2747.

3. Kearon C, Akl EA, Comerota AJ, et al. Antithrombotic therapy for VTE disease: Antithrombotic Therapy and Prevention of Thrombosis, 9th ed: American College of Chest Physicians Evidence-Based Clinical Practice Guidelines. Chest. 2012;141(2 Suppl):e419S-e494S.

4. Mozaffarian D, Benjamin EJ, Go AS, et al. Heart disease and stroke statistics - 2015 update: a report from the American Heart Association. Circulation. 2014;131(4):e29-e322.

5. Heit JA. Epidemiology of venous thromboembolism. Nat Rev Cardiol. 2015;12(8):464-474.

6. De Caterina R, Husted S, Wallentin L, et al. Vitamin K antagonists in heart disease: current status and perspectives (section III). Thromb Haemost. 2013;110(6):1087-1107.
7. Sjögren V, Grzymala-Lubanski B, Renlund H, et al. Safety and efficacy of well managed warfarin: a report from the Swedish quality register Auricula. Thromb Haemost. 2015;113(6):1370-1377.

8. Gallego P, Roldan V, Marín F, et al. Cessation of oral anticoagulation in relation to mortality and the risk of thrombotic events in patients with atrial fibrillation. Thromb Haemost. 2013;110(6):1189-1198.

9. Apostolakis S, Sullivan RM, Olshansky B, Lip GY. Factors affecting quality of anticoagulation control among patients with atrial fibrillation on warfarin: the SAMe-TT $\mathrm{R}_{2}$ score. Chest. 2013;144(5):1555-1563.

10. Proietti M, Lip GY. Simple decision-making between a vitamin K antagonist and a non-vitamin $\mathrm{K}$ antagonist oral anticoagulant: using the SAMe-TT $\mathrm{R}_{2}$ score. Eur Heart $J$ Cardiovasc Pharmacother. 2015;1(3):150-152.

11. Ruiz-Ortiz M, Bertomeu V, Cequier A, Marín F, Anguita M. Validation of the SAMe-TT $\mathrm{R}_{2}$ score in a nationwide population of nonvalvular atrial fibrillation patients on vitamin $\mathrm{K}$ antagonists. Thromb Haemost. 2015;114(4):695-701.

12. Fauchier L, Poli D, Olshansky B. The SAMe-TT $\mathrm{R}_{2}$ score and quality of anticoagulation in AF: can we predict which patient benefits from anticoagulation? Thromb Haemost. 2015;114(4):657-659.

13. Husted S, de Caterina R, Andreotti F, et al. Non-vitamin $\mathrm{K}$ antagonist oral anticoagulants (NOACs): no longer new or novel. Thromb Haemost. 2014;111(5):781-782.

14. Dzeshka MS, Lip GY. Non-vitamin K oral anticoagulants in atrial fibrillation: where are we now? Trends Cardiovasc Med. 2015;25(4): 315-336.

15. Granger CB, Alexander JH, McMurray JJ, et al. Apixaban versus warfarin in patients with atrial fibrillation. $N$ Engl J Med. 2011;365(11): 981-992.

16. Providência R, Grove EL, Husted S, Barra S, Boveda S, Morais J. A meta-analysis of phase III randomized controlled trials with novel oral anticoagulants in atrial fibrillation: comparisons between direct thrombin inhibitors vs. factor Xa inhibitors and different dosing regimens. Thromb Res. 2014;134(6):1253-1264.

17. Yeh CH, Gross PL, Weitz JI. Evolving use of new oral anticoagulants for treatment of venous thromboembolism. Blood. 2014;124(7):1020-1028.

18. Dentali F, Riva N, Crowther M, Turpie AG, Lip GY, Ageno W. Efficacy and safety of the novel oral anticoagulants in atrial fibrillation: a systematic review and meta-analysis of the literature. Circulation. 2012;126(20):2381-2391

19. Caldeira D, Rodrigues FB, Barra M, et al. Non-vitamin K antagonist oral anticoagulants and major bleeding-related fatality in patients with atrial fibrillation and venous thromboembolism: a systematic review and meta-analysis. Heart. 2015;101(15):1204-1211.

20. Giugliano RP, Ruff CT, Braunwald E, et al. Edoxaban versus warfarin in patients with atrial fibrillation. $N$ Engl J Med. 2013;369(22): 2093-2104.

21. Weitz JI, Eikelboom J. Incorporating edoxaban into the choice of anticoagulants for atrial fibrillation. Thromb Haemost. 2015;115(2): 257-270.

22. Furugohri T, Isobe K, Honda Y, et al. DU-176b, a potent and orally active factor $\mathrm{Xa}$ inhibitor: in vitro and in vivo pharmacological profiles. J Thromb Haemost. 2008;6(9):1542-1549.

23. Zafar MU, Vorchheimer DA, Gaztanaga J, et al. Antithrombotic effects of factor Xa inhibition with DU-176b: phase-I study of an oral, direct factor Xa inhibitor using an ex-vivo flow chamber. Thromb Haemost. 2007;98(4):883-888.

24. Douxfils J, Chatelain B, Chatelain C, Dogné JM, Mullier F. Edoxaban: impact on routine and specific coagulation assays - a practical laboratory guide. Thromb Haemost. 2015;115(2):368-381.

25. Ogata K, Mendell-Harary J, Tachibana M, et al. Clinical safety, tolerability, pharmacokinetics, and pharmacodynamics of the novel factor Xa inhibitor edoxaban in healthy volunteers. J Clin Pharmacol. 2010;50(7):743-753.

26. Lip GY, Agnelli G. Edoxaban: a focused review of its clinical pharmacology. Eur Heart J. 2014;35(28):1844-1855. 
27. Parasrampuria DA, Marbury T, Matsushima N, et al. Pharmacokinetics, safety, and tolerability of edoxaban in end-stage renal disease subjects undergoing haemodialysis. Thromb Haemost. 2015;113(4):719-727.

28. Hylek EM, Ko D, Cove CL. Gaps in translation from trials to practice: non-vitamin $\mathrm{K}$ antagonist oral anticoagulants (NOACs) for stroke prevention in atrial fibrillation. Thromb Haemost. 2014;111(5):783-788.

29. Chan NC, Paikin JS, Hirsh J, Lauw MN, Eikelboom JW, Ginsberg JS. New oral anticoagulants for stroke prevention in atrial fibrillation: impact of study design, double counting and unexpected findings on interpretation of study results and conclusions. Thromb Haemost. 2014;111(5):798-807.

30. Connolly SJ, Ezekowitz MD, Yusuf S, et al. Dabigatran versus warfarin in patients with atrial fibrillation. $N$ Engl J Med. 2009;361(12): 1139-1151.

31. Patel MR, Mahaffey KW, Garg J, et al. Rivaroxaban versus warfarin in nonvalvular atrial fibrillation. N Engl J Med. 2011;365(10):883-891.

32. Ruff CT, Giugliano RP, Antman EM, et al. Evaluation of the novel factor Xa inhibitor edoxaban compared with warfarin in patients with atrial fibrillation: design and rationale for the Effective aNticoaGulation with factor xA next GEneration in Atrial Fibrillation-Thrombolysis In Myocardial Infarction study 48 (ENGAGE AF-TIMI 48). Am Heart J. 2010;160(4):635-641.

33. Weitz JI, Connolly SJ, Patel I, et al. Randomised, parallel-group, multicentre, multinational phase 2 study comparing edoxaban, an oral factor $\mathrm{Xa}$ inhibitor, with warfarin for stroke prevention in patients with atrial fibrillation. Thromb Haemost. 2010;104(3):633-641.

34. Yamashita T, Koretsune Y, Yasaka M, et al. Randomized, multicenter, warfarin-controlled phase II study of edoxaban in Japanese patients with non-valvular atrial fibrillation. Circ J. 2012;76(8):1840-1847.

35. Chen J, Zhuang X, Long M, Su C, Wang L. Efficacy and safety of edoxaban in nonvalvular atrial fibrillation: a meta-analysis of randomized controlled trials. J Stroke Cerebrovasc Dis. 2015;24(12):2710-2719.

36. Ruff CT, Giugliano RP, Braunwald E, et al. Association between edoxaban dose, concentration, anti-factor Xa activity, and outcomes: an analysis of data from the randomised, double-blind ENGAGE AF-TIMI 48 trial. Lancet. 2015;385(9984):2288-2295.

37. Blann AD, Banerjee A, Lane DA, Torp-Pedersen C, Lip GY. Net clinical benefit of edoxaban versus no treatment in a "real world" atrial fibrillation population: a modelling analysis based on a nationwide cohort study. Int J Cardiol. 2015;201:693-698.

38. Lip GY, Mitchell SA, Liu X, et al. Relative efficacy and safety of non-vitamin $\mathrm{K}$ oral anticoagulants for non-valvular atrial fibrillation: network meta-analysis comparing apixaban, dabigatran, rivaroxaban and edoxaban in three patient subgroups. Int J Cardiol. 2015;204:88-94.

39. Skjøth F, Larsen TB, Rasmussen LH, Lip GY. Efficacy and safety of edoxaban in comparison with dabigatran, rivaroxaban and apixaban for stroke prevention in atrial fibrillation: an indirect comparison analysis. Thromb Haemost. 2014;111(5):981-988.

40. Blann AD, Skjøth F, Rasmussen LH, Larsen TB, Lip GY. Edoxaban versus placebo, aspirin, or aspirin plus clopidogrel for stroke prevention in atrial fibrillation: an indirect comparison analysis. Thromb Haemost. 2015;114(2):403-409.

41. Shields AM, Lip GY. Choosing the right drug to fit the patient when selecting oral anticoagulation for stroke prevention in atrial fibrillation. J Intern Med. 2015;278(1):1-18.
42. Lip GY, Merino J, Ezekowitz M, et al. A prospective evaluation of edoxaban compared to warfarin in subjects undergoing cardioversion of atrial fibrillation: the EdoxabaN vs. warfarin in subjectS UndeRgoing cardiovErsion of Atrial Fibrillation (ENSURE-AF) study. Am Heart J. 2015;169(5):597e5-604.e5.

43. Prandoni P. Treatment of patients with acute deep vein thrombosis and/ or pulmonary embolism: efficacy and safety of non-VKA oral anticoagulants in selected populations. Thromb Res. 2014;134(2):227-233.

44. Hirschl M, Kundi M. New oral anticoagulants in the treatment of acute venous thromboembolism - a systematic review with indirect comparisons. Vasa. 2014;43(5):353-364.

45. Raskob G, Büller H, Prins M, et al. Edoxaban for the long-term treatment of venous thromboembolism: rationale and design of the Hokusaivenous thromboembolism study - methodological implications for clinical trials. J Thromb Haemost. 2013;11(7):1287-1294.

46. Büller HR, Décousus H, Grosso MA, et al. Edoxaban versus warfarin for the treatment of symptomatic venous thromboembolism. $N$ Engl $J$ Med. 2013;369(15):1406-1415.

47. Bounameaux H, Camm AJ. Edoxaban: an update on the new oral direct factor Xa inhibitor. Drugs. 2014;74(11):1209-1231.

48. van Es N, Di Nisio M, Bleker SM, et al. Edoxaban for treatment of venous thromboembolism in patients with cancer. Thromb Haemost. 2015;114(6):1268-1276.

49. Nakamura M, Wang YQ, Wang C, et al. Efficacy and safety of edoxaban for treatment of venous thromboembolism: a subanalysis of East Asian patients in the Hokusai-VTE trial. J Thromb Haemost. 2015;13(9):1606-1614

50. Proietti M, Lip GY. Antidotes to non-vitamin K oral anticoagulants: necessary or not? Expert Opin Pharmacother. 2015;16(11):1573-1576.

51. Niessner A, Tamargo J, Morais J, et al. Reversal strategies for nonvitamin K antagonist oral anticoagulants: a critical appraisal of available evidence and recommendations for clinical management - a joint position paper of the European Society of Cardiology Working Group on Cardiovascular Pharmacotherapy and European Society of Cardiology Working Group on Thrombosis. Eur Heart J. Epub 2015 Dec 24.

52. Glund S, Moschetti V, Norris S, et al. A randomised study in healthy volunteers to investigate the safety, tolerability and pharmacokinetics of idarucizumab, a specific antidote to dabigatran. Thromb Haemost. 2015;113(5):943-951

53. Pollack CV, Reilly PA, Bernstein R, et al. Design and rationale for RE-VERSE AD: a phase 3 study of idarucizumab, a specific reversal agent for dabigatran. Thromb Haemost. 2015;114(1):198-205.

54. Pollack CV, Reilly PA, Eikelboom J, et al. Idarucizumab for dabigatran reversal. N Engl J Med. 2015;373(6):511-520.

55. Siegal DM, Curnutte JT, Connolly SJ, et al. Andexanet alfa for the reversal of factor Xa inhibitor activity. $N$ Engl J Med. 2015;373(25): 2413-2424.

56. Hankey GJ. Unanswered questions and research priorities to optimise stroke prevention in atrial fibrillation with the new oral anticoagulants Thromb Haemost. 2014;111(5):808-816.

57. Wang KL, Lip GY, Lin SJ, Chiang CE. Non-vitamin K antagonist oral anticoagulants for stroke prevention in Asian patients with nonvalvular atrial fibrillation: meta-analysis. Stroke. 2015;46(9):2555-2561.
Vascular Health and Risk Management

\section{Publish your work in this journal}

Vascular Health and Risk Management is an international, peerreviewed journal of therapeutics and risk management, focusing on concise rapid reporting of clinical studies on the processes involved in the maintenance of vascular health; the monitoring, prevention and treatment of vascular disease and its sequelae; and the involvement of

\section{Dovepress}

metabolic disorders, particularly diabetes. This journal is indexed on PubMed Central and MedLine. The manuscript management system is completely online and includes a very quick and fair peer-review system, which is all easy to use. Visit http://www.dovepress.com/ testimonials.php to read real quotes from published authors. 